\title{
Automation in U. S. East Asian Libraries in the United States: A Review and Assessment
}

\section{Sarah Su-erh Elman}

The RLIN CJK system has been in use for more than six years and the OCLC CJK350 system for more than three years. Have they brought the holdings of East Asian collections into the bibliographic mainstream, as they were expected to do? This paper briefly examines the history and special features of these two CJK systems. A national survey also was conducted among academic and research member libraries in the United States to learn how these systems have been incorporated into their local automated library systems. Findings of the survey indicate that the advantages of the two systems are not fully delivered to the general user because local automated library systems still are incapable of processing and displaying non-Roman languages. More efforts are needed to develop this capability in order to integrate fully non-Roman collections into the general collection.

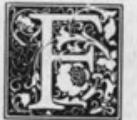

rom the experimental mainframe systems in the 1960s to the various mini- and microcomputer-based, integrated, and stand-alone systems that are available today, the development of automated library systems has come a long way and has accomplished a great deal. ${ }^{1}$ However, in the first two decades of their development, most attention was focused on the automatic processing of Englishand other Roman-language materials.

The ideographic nature of East Asian languages, especially Chinese, made East Asian libraries only observers of library automation until the development of the Research Library Information Network-Chinese, Japanese, and Korean (RLIN CJK) system in 1983 and the Online Computer Library Center-
Chinese, Japanese, and Korean (OCLC CJK350) system in 1986. The implementation of these two systems has implications for East Asian libraries, in particular, and scholarly communities, in general. They not only assist member libraries in the automation of CJK materials, but foster national and international information exchanges and resource sharing of these materials. As Research Libraries Group (RLG) vice president John W. Haegar says, "The implementation of CJK placed a marker at the end of the old world and the beginning of a new one for East Asian libraries, and brought their holdings into the bibliographic mainstream."

After several years of implementation, it is useful to examine the current use of these two CJK systems in the biblio-

Sarah Su-erh Elman is a 1990 graduate of the Graduate School of Library and Information Science, University of California, Los Angeles, California. Currently, she is traveling abroad and working for both the Modern History Institute Library, Academia Sinica, and the National Central Library in Taiwan. 
graphic community as a whole to see whether they are fully utilized by the institutions that have purchased them. The major purpose of this research project is to learn how academic and research libraries in the United States incorporate the RLIN CJK and the OCLC CJK350 systems into their local systems. I have collected for analysis information related to functions, merits, and weaknesses of the two systems, as well as to their relationship with local bibliographic systems.

Three similar surveys have been performed, one each by Karen T. Wei (1986), Wen-kai Kung (1986), and Hee-Jung Lee (1985). ${ }^{3}$ However, these surveys were conducted before the OCLC CJK350 system was implemented. This project updates their findings.

\section{RLIN CJK AND OCLC CJK350}

Much has been written about the history of the development and the characteristics of these two systems by authors such as John W. Haegar, Jay Lee, Alan Tucker, Andrew Wang, and Karen T. Wei. ${ }^{4}$ I will not repeat their efforts, but only mention some of the important features of these systems.

\section{RLIN CJK}

The hardware of the first-generation RLIN CJK system is a CJK cluster composed of a cluster controller, one to four CJK terminals, and an optional printer. The RLIN CJK uses a specially designed keyboard with a total of 179 keys, of which ten are control keys, 133 are character-composing keys, and 36 are function keys. ${ }^{5}$ In September 1988, RLG introduced a second-generation RLIN CJK terminal, the MultiScript Workstation (MSW), which is an IBM PC/ATclass machine configured to work as a standard RLIN terminal, but that also supports the processing of bibliographic information in Chinese, Japanese, Korean, Hebrew, and Cyrillic scripts. ${ }^{6}$ The new MSW not only has improved hardware and software, but costs much less than its predecessor (approximately $\$ 6,000$, compared with $\$ 27,000$ for the previous CJK cluster).
RLIN CJK's input method is based on a character-composing system for both Chinese and Korean characters. Users have to key in the character components in the correct keystroke sequence to retrieve desired characters. Familiarity with the writing sequence of characters is important to operate the RLIN CJK efficiently. RLIN CJK provides various access points, such as commonly used standard numbers and codes, author, title, corporate body, and subject, and several display formats. Truncation, Boolean logic operators, and qualifiers can also be used in searching.

Truncation, Boolean logic operators, and qualifiers can also be used in searching.

Since the Library of Congress entered the first CJK record into RLIN on September 12, 1983, the total number of CJK records in RLIN has increased rapidly and has exceeded 400,000 as of spring of $1990 .{ }^{7}$ Currently, the Library of Congress and 23 academic and research libraries in the United States use the RLIN CJK system.

\section{OCLC CJK350}

Unlike RLIN, which designed a completely new system for CJK materials, OCLC modified its existing IBM PC/XT configurated OCLC M300 workstation to accommodate the capability of processing and displaying CJK characters. When linked with the OCLC online system, the workstation is capable of processing information in Chinese, Japanese, Korean, English, French, German, Malay, Spanish, Vietnamese, and other Romanalphabet languages. The workstation also can be used as a stand-alone microcomputer. $^{8}$

OCLC CJK350 provides both character-based and pronunciation-based input methods. However, its characterbased input method, Tsang-chieh, is different from that of RLIN. Instead of pressing the character component keys directly to retrieve desired characters, 
users key in, in the correct sequence, the Roman alphabets that represent the character components. OCLC CJK350 provides pronunciation-based input methods for four Romanization schemes: WadeGiles and Pinyin for Chinese characters; modified Hepburn for Japanese kanji, katakana, and hiragana; and McCuneReischauer for Korean hancha and hangul. ${ }^{9}$

The OCLC CJK350 provides fewer access points than the RLIN CJK system. Only commonly used standard numbers and codes, titles, authors (personal or corporate), and combinations of authors and titles are searchable. (On January 6, 1990, OCLC released its online reference system, the EPIC service, which provides keyword or phrase and subject searches, Boolean operators, truncations, and many other useful features. ${ }^{10}$ However, it can search and display Roman or Romanized records only. OCLC CJK350 users do not benefit directly from it.) Qualifiers such as format and year(s) of publication can be used in searching. Although group display, collective display, and truncated record display are used when more than one record is retrieved, the only display format for a single CJK record is the MARC format. OCLC CJK350 also allows users to print out locally catalog cards, with both Romanized and vernacular information.

Officially introduced in January 1987, the OCLC CJK350 system had 70 user libraries worldwide as of October 1989, including 20 academic libraries in the United States." The total number of unique CJK records in the OCLC Online Union Catalog had exceeded 320,000 as of January 1990.

\section{Comparisons}

The most important merits of the RLIN CJK system are the size of its database and its powerful search capabilities. RLIN CJK user libraries are major East Asian academic and research libraries, holding approximately $60 \%$ of the total East Asian collections in the United States. RLIN CJK also provides Boolean logic operators, truncation, and keyword and subject search capabilities.
These capabilities make it possible to use RLIN CJK as an online public access catalog, provided users can overcome the difficulty of its input methods.

The most important merits of the OCLC CJK350 system are its diversified input methods and its card production capability. The different input methods are convenient for users of various backgrounds. The card production capability is a great help for most East Asian libraries because most of them still rely on the card catalog, with vernacular characters, for public access.

The most important merits of the OCLC CJK350 system are its diversified input methods and its card production capability.

In addition to incorporating member libraries' contributions to original cataloging and record upgrading, both OCLC and RLG are seeking records from other sources, such as institutions in China, Japan, and Taiwan. If this upgrading is accomplished, the two systems will eventually provide access to CJK materials worldwide. Meanwhile, RLIN and OCLC have agreed to exchange their records and to cooperate in the implementation of standards for computer linkages. ${ }^{12}$ If further communication and cooperation between these two major bibliographic utilities occur, both East Asian libraries and scholarly communities in the United States can greatly benefit.

\section{RESEARCH QUESTIONS}

Understanding the status of RLIN and OCLC CJK systems in the greater bibliographic community requires knowledge of how these systems are used in individual user institutions. This research addresses the following questions:

1. What functions do the RLIN CJK and OCLC CJK350 systems serve for member libraries?

2. What are the merits and weaknesses of these CJK systems, as seen by member libraries? 
3. What are the relationships between these two CJK systems and member libraries' local automated library systems?

4. What direction is automation in East Asian libraries heading from this point? Is it possible, in the near future, to integrate these two CJK systems with member libraries' local automated library systems to perform total online library services? What are the major barriers?

\section{RESEARCH METHODS}

To investigate these questions, a national survey among academic and research member libraries regarding both the RLIN CJK and the OCLC CJK350 systems was conducted. A questionnaire was designed to gather information on the following areas:

A. General information on the East Asian collection: the location of the collection, the size of the collection and the staff, and the public access mechanism to the collection;

B. Information on the use of the RLIN and OCLC CJK systems: the date the CJK system was installed, the number of terminals used, the functions the CJK system serves for the collection, and the benefits and problems with regard to using the CJK system;

C. Information on the local automated library system: the name of the local system, when it was implemented, how it was developed, what functions it serves, and its capability of handling non-Roman scripts (If the local system cannot handle non-Roman scripts, what are the problems? Is the institution going to develop the capability? If yes, when and how? If no, why not?); and

D. Relations between the local automated library system and the CJK system: is the CJK system parallel to the local system? Or is the CJK system used mainly to download records to the local system? If so, how does it work out? How are the vernacular characters treated?
RLIN and OCLC provided the member lists of these two systems. In midJanuary 1990, questionnaires were sent to 43 academic and research member libraries of these two systems in the United States-20 for OCLC CJK350, 23 for RLIN CJK. However, because two libraries at Columbia University use the RLIN CJK system, the number of institutions included in this research is actually 42 . Follow-up questionnaires were sent out in late February. The data-gathering process was completed in mid-March, with the return rate close to $90 \%$ (38 out of 42 institutions returned the questionnaire).

\section{SURVEY RESULTS}

The survey results are described in the following text and tables.

\section{A. General Information on the East Asian Collections}

Table 1 shows the location and language coverage of the responding libraries; table 2 shows the size of their collections (monographs only) versus the size of their staffs.

Physical Location. Among 38 respondents, $30(79 \%)$ reported having either a separate East Asian library or a separate collection housed in the general library (see table 1).

Language Coverage. Thirty-seven libraries answered the question on language coverage. All of them have Chinese and Japanese materials; 32 $(86 \%)$ have Korean materials; and 10 $(26 \%)$ have some materials in languages other than CJK (see table 1).

Size of Collections. Thirty-five libraries reported on the size of their collections. The size of the other three collections was estimated based on the statistics gathered by the task force for annual review and survey of library resources of the committee for East Asian libraries in 1988. The size of monographic collections ranges from 15,000 to 734,000 volumes (most respondents did not provide the number of monographic titles they have), with 21 (55\%) libraries having collections of more than 100,000 volumes. Eighteen $(47 \%)$ libraries have more than 1,000 serials titles. Thirteen 
TABLE 1

PHYSICAL LOCATION AND LANGUAGE COVERAGE

No. of Librarians

$\%$

Physical locations:

Separate collection

79

Integrated

8

21

Languages covered:

Chinese

Japanese

Korean

32

86

Other languages

10

26

TABLE 2

COLLECTION SIZE VS. STAFF SIZE

\begin{tabular}{crrcc}
\hline & & \multicolumn{3}{c}{ Collection Size (unit: 1,000 volumes) } \\
\cline { 3 - 5 } Staff Size & & $<100$ & $100-299$ & $>300$ \\
\hline \multirow{5}{*}{ Pro } & $0-2.0$ & 13 & 4 & 0 \\
& $2.5-4.0$ & 3 & 5 & 2 \\
& $4.1-6.0$ & 1 & 2 & 1 \\
& $6.1-8.0$ & 0 & 0 & 4 \\
& $8.5+$ & 0 & 1 & 2 \\
& $0-2.0$ & 11 & 0 & 0 \\
& $2.1-4.0$ & 4 & 7 & 0 \\
& $4.1-6.0$ & 1 & 3 & 0 \\
& $6.1-8.0$ & 1 & 0 & 0 \\
& $8.1-10.0$ & 0 & 0 & 6 \\
\hline
\end{tabular}

PRO: Professional staff

\section{NONPRO: Non-professional staff}

(34\%) libraries reported having microform collections.

Size of Staff. The staff size of responding libraries ranges from 1.26 to 35.65 fulltime employees. Twenty-seven (71\%) respondents have 4 or fewer professional librarians; 2 (5\%) libraries have more than 10 professional librarians. Only $7(18 \%)$ libraries have more professional librarians than nonprofessional staff. Apparently, except for the two largest collections, the size of staff is not always proportionate to the size of the collection (see table 2).

Public Access Mechanism. All 38 responding libraries have a card catalog as a public access mechanism for CJK materials. In addition to a card catalog, 8
(21\%) libraries have a microform catalog; 28 (74\%) libraries have local online catalog systems (providing Romanized bibliographic information); 22 (58\%) libraries use either the OCLC or the RLIN CJK system; and 4 (11\%) libraries have other mechanisms, such as a printed catalog.

\section{B. Information on the Use of CJK Systems}

Systems Used. Eighteen OCLC CJK350 members and 20 RLIN CJK members responded to the questionnaire. Among 17 small collections (fewer than 100,000 volumes), 9 (24\%) use OCLC CJK350 and 8 (21\%) use RLIN CJK; among 12 me- 
TABLE 3

NUMBER OF CJK SYSTEM INSTALLATIONS

IN LIBRARIES OF DIFFERENT SIZES, 1982-1989

\begin{tabular}{lccccccc}
\hline & \multicolumn{2}{c}{ Systems } & & \multicolumn{3}{c}{ Collection Size* } \\
\cline { 2 - 3 } \cline { 5 - 6 } Date & OCLC & RLIN & Total & $<100$ & $100-299$ & $>300$ \\
\hline N.D. & 1 & 1 & 2 & 1 & 1 & 0 \\
1982 & 0 & 2 & & 2 & 0 & 0 & 2 \\
1983 & 0 & 5 & 5 & 1 & 0 & 4 \\
1984 & 0 & 3 & & 3 & 2 & 1 & 0 \\
1985 & 0 & 4 & & 4 & 1 & 2 & 1 \\
1986 & 7 & 0 & & 7 & 3 & 4 & 0 \\
1987 & 1 & 1 & 2 & 1 & 0 & 1 \\
1988 & 6 & 1 & & 7 & 3 & 3 & 1 \\
1989 & 3 & 3 & 6 & 5 & 1 & 0 \\
Total & 18 & 20 & 38 & 17 & 12 & 9 \\
\hline
\end{tabular}

*Unit: 1,000 volumes

dium collections $(100,000$ to 299,000 volumes), 7 (18\%) are OCLC CJK350 members and 5 (13\%) are RLIN CJK members; among 9 large collections $(300,000$ or more volumes), 2 (5\%) use OCLC CJK350 and 7 (18\%) use RLIN CJK. That large CJK collections tend to use the RLIN CJK system is not surprising because most of them are RLG members.

Year of Installation. Table 3 shows the number of CJK systems installed in respondents' libraries, in correspondence with their collection sizes, and the year the installation took place.

No sign exists of significant change in the number of installations over these past years, except for the decrease in 1987. Nevertheless, the shift of installations from RLIN to OCLC in 1986, when the OCLC CJK350 was first released, is interesting. The year 1988 also was a successful year for OCLC. Although both systems had the same number of installations in 1988 , it is too early to predict the future. When comparing the year of the CJK system installation with the size of each collection, large collections, in general, automated their systems earlier than medium and small collections; however, this is not an absolute condition. For example, four small collections installed CJK systems before 1986.
Number of Terminals Used. Table 4 shows the number of terminals used in 36 responding libraries. Among them, 14 $(39 \%)$ have one terminal, $10(28 \%)$ have two terminals, $6(17 \%)$ have three terminals, $5(14 \%)$ have 4 terminals, $1(3 \%)$ has 6 terminals, and 2 libraries did not provide the information. The total number of terminals in use is at least 80 , assuming that the two libraries that did not provide data have one or more terminals.

Functions CJK Systems Serve. Table 5 shows the library functions that the two CJK systems serve for 37 responding libraries (multiple answers). All responding libraries use CJK systems for cataloging; 17 (46\%) use them for an online public catalog (although this number is not consistent with the number reported in the above section on public access mechanisms, in which $58 \%$ of the respondents reported using CJK systems for public access; perhaps some respondents misinterpreted one of the questions); $13(35 \%)$ use them for interlibrary loan purposes; $6(16 \%)$ use them for acquisitions-related tasks (e.g., preorder searching and record verification); and only $1(3 \%)$ library reported using the CJK system for serials control.

Benefits of CJK Systems. Originally, the question was designed to have re- 
TABLE 4

NUMBER OF TERMINALS IN USE

\begin{tabular}{cc}
\hline No. of Terminals & No. of Libraries \\
\hline 1 & 14 \\
2 & 10 \\
3 & 6 \\
4 & 5 \\
6 & 1 \\
No data & 2 \\
\hline
\end{tabular}

TABLE 5

LIBRARY FUNCTIONS CJK SYSTEMS SERVE $(\mathrm{N}=37)$

\begin{tabular}{lcccc}
\hline Functions & OCLC & RLIN & Total & \multicolumn{1}{c}{$\%$} \\
\hline Acquisitions & 3 & 3 & 6 & 16 \\
$\begin{array}{l}\text { Cataloging } \\
\begin{array}{l}\text { Online public } \\
\quad \text { catalog }\end{array}\end{array}$ & 17 & 20 & 37 & 100 \\
$\begin{array}{l}\text { Serials control } \\
\begin{array}{l}\text { Inter-library } \\
\text { loan }\end{array}\end{array}$ & 0 & 11 & 17 & 46 \\
\hline
\end{tabular}

spondents rank each point, from one to five, according to its importance for individual libraries. However, some respondents misunderstood the question and ranked them against one another; other respondents checked the points they found to be important. As a result, the method of interpreting the results had to be altered. I first separated the 37 respondents into two groups: those who answered according to my intention I labeled group A (consisting of 26 respondents, $70 \%$ of the total), and the rest I labeled group B. Only rank values from group A were taken for calculation of range and medians. Meanwhile, I counted the number of votes for each benefit element from both groups. As long as a library selected a benefit element, whether ranked or checked, I counted it as one vote for that benefit element.

Tables $6 a, 6 b$, and $6 c$ show the results for the OCLC CJK350, the RLINCJK, and the combination of both. According to tables $6 a$ and $6 b$, the members of both CJK systems seem to be in consensus on the major benefits of CJK systems, except that RLIN CJK members ranked "access to other collections" much higher than did OCLC members. This probably is due to the RLINCJK's inclusion of records (for the same title) from different libraries, while the OCLC CJK350 only retains a unique record for a title with holding information of others attached. The RLIN CJK's practice enables users to access more detailed holding information, such as call number and editions, from other libraries. Another factor could be that RLIN CJK members have more interlibrary loan activities than OCLC CJK350 members (see table 5).

For group A of the combined CJK system members (see table $6 \mathrm{c}$ ), the most important benefit of the two systems is increased cataloging productivity, followed by authority control and access to both other libraries' and each local

TABLE 6A

MAJOR BENEFITS OF OCLC CJK350

\begin{tabular}{lcccc}
\hline & \multicolumn{2}{c}{ Group A } & \multicolumn{2}{c}{ Group A \& B } \\
\cline { 2 - 5 } Major Benefits & Med. & Range & No. of Votes & $\%$ \\
\hline $\begin{array}{l}\text { Increased cataloging } \\
\text { productivity }\end{array}$ & 5 & $2-5$ & 15 & 88 \\
$\begin{array}{l}\text { Authority control } \\
\text { Access to local holdings }\end{array}$ & 4 & $3-5$ & 12 & 71 \\
Access to other collections & 3 & $1-5$ & 14 & 82 \\
Improved staff morale & 3 & $1-5$ & 15 & 88 \\
Improved library image & 3 & $1-5$ & 14 & 82 \\
& 4 & $1-5$ & 14 & 82 \\
\hline
\end{tabular}


TABLE 6B

MAJOR BENEFITS OF RLIN CJK

\begin{tabular}{lcccc}
\hline & \multicolumn{2}{c}{ Group A } & \multicolumn{2}{c}{ Group A \& B } \\
\cline { 2 - 5 } Major Benefits & Med. & Range & No. of Votes & $\%$ \\
\hline $\begin{array}{l}\text { Increased } \\
\text { cataloging } \\
\text { productivity }\end{array}$ & 5 & $2-5$ & 20 & 100 \\
$\begin{array}{c}\text { Authority control } \\
\begin{array}{c}\text { Access to local } \\
\text { holdings }\end{array}\end{array}$ & 5 & $1-5$ & 17 & 85 \\
$\begin{array}{c}\text { Access to other } \\
\text { collections }\end{array}$ & 5 & $1-5$ & 19 & 95 \\
$\begin{array}{c}\text { Improved staff } \\
\text { morale }\end{array}$ & 3 & $1-5$ & 19 & 95 \\
$\begin{array}{c}\text { Improved library } \\
\text { image }\end{array}$ & 3 & $1-5$ & 13 & 80 \\
\hline
\end{tabular}

TABLE 6C

MAJOR BENEFITS OF OCLC \& RLIN CJK SYSTEMS

\begin{tabular}{lcccc}
\hline \multirow{2}{*}{ Major Benefits } & \multicolumn{2}{c}{ Group A } & \multicolumn{2}{c}{ Group A \& B } \\
\cline { 2 - 5 } Increased cataloging productivity & Med. & Range & No. of Votes & $\%$ \\
Authority control & 5 & $2-5$ & 35 & 95 \\
Access to local holdings & 5 & $1-5$ & 25 & 68 \\
Access to other collections & 4 & $1-5$ & 33 & 89 \\
Improved staff morale & 4 & $1-5$ & 33 & 89 \\
Improved library image & 3 & $1-5$ & 27 & 73 \\
& 3 & $1-5$ & 30 & 81 \\
\hline
\end{tabular}

library's holding information. Conversely, when judged by the number of votes, these benefits are ranked, starting with the most popular, as: increased cataloging productivity, access to local and other libraries' holding information, improved library image, improved staff morale, and authority control.

Major Problems of CJK Systems. The question concerning major problems of CJK systems confused respondents in much the same way as did the question about CJK system benefits. I therefore used the method described earlier to analyze the data answering this question. Twenty-seven (75\%) respondents in group A answered this question correctly. The statistical results of major problems of the OCLC CJK350, the RLIN
CJK, and the combination of both are shown in tables $7 \mathrm{a}, 7 \mathrm{~b}$, and $7 \mathrm{c}$.

Tables $7 \mathrm{a}$ and $7 \mathrm{~b}$ indicate that the members of the two systems have different concerns, although there are similarities also. OCLC CJK350 members ranked "searching methods" much higher than did RLIN CJK members. This is, I think, because of the OCLC CJK350's lack of key word, subject, and other related searching capabilities. Yet RLIN CJK members ranked "high costs" much higher than did OCLC CJK350 members. This is not surprising because most RLIN CJK members still use firstgeneration terminals; when the new MSWs are widely installed, the situation will improve significantly. What is surprising is that members of both the RLIN 
TABLE 7A

MAJOR PROBLEMS OF OCLC CJK350

\begin{tabular}{|c|c|c|c|c|}
\hline \multirow[b]{2}{*}{ Problems } & \multicolumn{2}{|c|}{ Group A } & \multicolumn{2}{|c|}{ Group A \& B } \\
\hline & Med. & Range & No. of Votes & $\%$ \\
\hline Slow response time & 3 & $1-5$ & 13 & 76 \\
\hline Quality of records & 3 & $1-5$ & 15 & 88 \\
\hline Difficult to master & 1.5 & $1-4$ & 13 & 76 \\
\hline Searching methods & 4 & $1-5$ & 16 & 94 \\
\hline Display formats & 2 & $1-5$ & 12 & 71 \\
\hline Inadequate for public use & 3.5 & $1-5$ & 13 & 76 \\
\hline System downtime & 2 & $1-4$ & 12 & 71 \\
\hline Hardware breakdowns & 2 & $1-3$ & 13 & 76 \\
\hline High costs & 2 & $1-5$ & 12 & 71 \\
\hline Find experienced employees & 3 & $1-5$ & 12 & 71 \\
\hline \multirow[t]{2}{*}{ Support from RLG/OCLC } & 2 & $1-4$ & 12 & 71 \\
\hline & \multicolumn{2}{|c|}{$\mathrm{n}=12$} & \multicolumn{2}{|c|}{$\mathrm{n}=17$} \\
\hline
\end{tabular}

TABLE 7B

MAJOR PROBLEMS OF RLIN CJK

\begin{tabular}{llccc}
\hline & \multicolumn{2}{c}{ Group A } & \multicolumn{2}{c}{ Group A \& B } \\
\cline { 2 - 5 } Problems & Med. & Range & No. of Votes & $\%$ \\
\hline Slow response time & 2 & $1-5$ & 18 & 90 \\
Quality of records & 3 & $1-5$ & 17 & 85 \\
Difficult to master & 2.5 & $1-5$ & 16 & 80 \\
Searching methods & 1 & $1-4$ & 14 & 70 \\
Display formats & 1 & $1-4$ & 9 & 45 \\
Inadequate for public use & 3 & $1-5$ & 15 & 75 \\
System downtime & 2 & $1-5$ & 15 & 75 \\
Hardware breakdowns & 1 & $1-5$ & 15 & 75 \\
High costs & 3 & $2-5$ & 18 & 90 \\
Find experienced employees & 4 & $1-5$ & 15 & 75 \\
Support from RLG/OCLC & 1 & $1-2$ & 11 & 55 \\
\end{tabular}

CJK and the OCLC CJK350 selected "inadequate for public use" as one of the three most serious problems of the systems, despite the fact that the OCLC CJK350 provides various input methods and the RLIN CJK provides various display formats. This is an issue that needs further investigation.

For group A of the combined CJK system members (see table 7c), the three greatest problems of the CJK systems are its inadequacy for public use, its high costs, and the difficulty in finding employees experienced with the system. The three most commonly chosen problems are the quality of records, the high costs, and the available searching methods.

\section{Information on Local Automated Library Systems}

Among the 38 respondents, 4 (11\%) do not have local automated library sys- 
TABLE 7C

MAJOR PROBLEMS OF OCLC \& RLIN CJK SYSTEMS

\begin{tabular}{|c|c|c|c|c|}
\hline \multirow[b]{2}{*}{ Problems } & \multicolumn{2}{|c|}{ Group A } & \multicolumn{2}{|c|}{ Group A \& B } \\
\hline & Med. & Range & No. of Votes & $\%$ \\
\hline Slow response time & 2 & $1-5$ & 28 & 76 \\
\hline Quality of records & 3 & $1-5$ & 32 & 86 \\
\hline Difficult to master & 2 & $1-5$ & 29 & 78 \\
\hline Searching methods & 3 & $1-5$ & 30 & 81 \\
\hline Display formats & 2 & $1-5$ & 23 & 62 \\
\hline Inadequate for public use & 3 & $1-5$ & 28 & 76 \\
\hline System downtime & 2 & $1-5$ & 27 & 73 \\
\hline Hardware breakdowns & 1 & $1-5$ & 29 & 78 \\
\hline High costs & 3 & $1-5$ & 31 & 84 \\
\hline Find experienced employees & 3 & $1-5$ & 27 & 73 \\
\hline \multirow[t]{2}{*}{ Support from RLG/OCLC } & 1 & $1-4$ & 23 & 62 \\
\hline & \multicolumn{2}{|c|}{$\mathrm{n}=27$} & \multicolumn{2}{|c|}{$\mathrm{n}=37$} \\
\hline
\end{tabular}

tems yet. On the other hand, $10(26 \%)$ institutions have more than one system for different library functions. The majority of respondents have integrated local automated library systems.

Years of Automation. Table 8 shows the years in which 34 institutions automated their library operations. For institutions having more than one automated system, the earliest years are chosen as the starting years. The majority $(63 \%)$ of the responding institutions automated their library functions between 1985 and 1989 . In order to discover whether relationships exist between the automation of general collections and CJK collections, the years in which responding institutions automated their general and CJK collections are drawn and tabulated in table 9. From the diagram, there is not enough evidence to support the assumption that those libraries that automated their general collections early also automated their CJK collections early. They are largely independent events. Another surprising finding is that 16 institutions automated their CJK collections before they automated their general collections.

Development of Local Systems. Table 10 shows the methods of development of responding institutions' local automated library systems. The majority
(65\%) of these local automated library systems are turn-key systems or modified commercial systems. Only $29 \%$ of the systems were developed in-house (most of these institutions have CJK collections exceeding 100,000 volumes).

Functions of Local Systems. Table 11 shows the library functions local automated library systems serve. Among 34 respondents, only $8(25 \%)$ institutions have automated all functions listed. Eighteen (53\%) institutions have automated the four basic library functionsthat is, acquisitions, circulation, online public catalog, and serials control. Nevertheless, the majority of respondents have online public catalog, circulation, and acquisitions systems. A few institutions' local systems also serve

TABLE 8

YEARS OF AUTOMATION

\begin{tabular}{lr}
\hline Year & No. of institutions \\
\hline N.D. & 4 \\
$1970-1974$ & 1 \\
$1975-1979$ & 4 \\
$1980-1984$ & 5 \\
$1985-1989$ & 19 \\
1990 & 1 \\
\hline
\end{tabular}


TABLE 9

YEARS OF AUTOMATING GENERAL AND CJK COLLECTIONS

CJK Collections

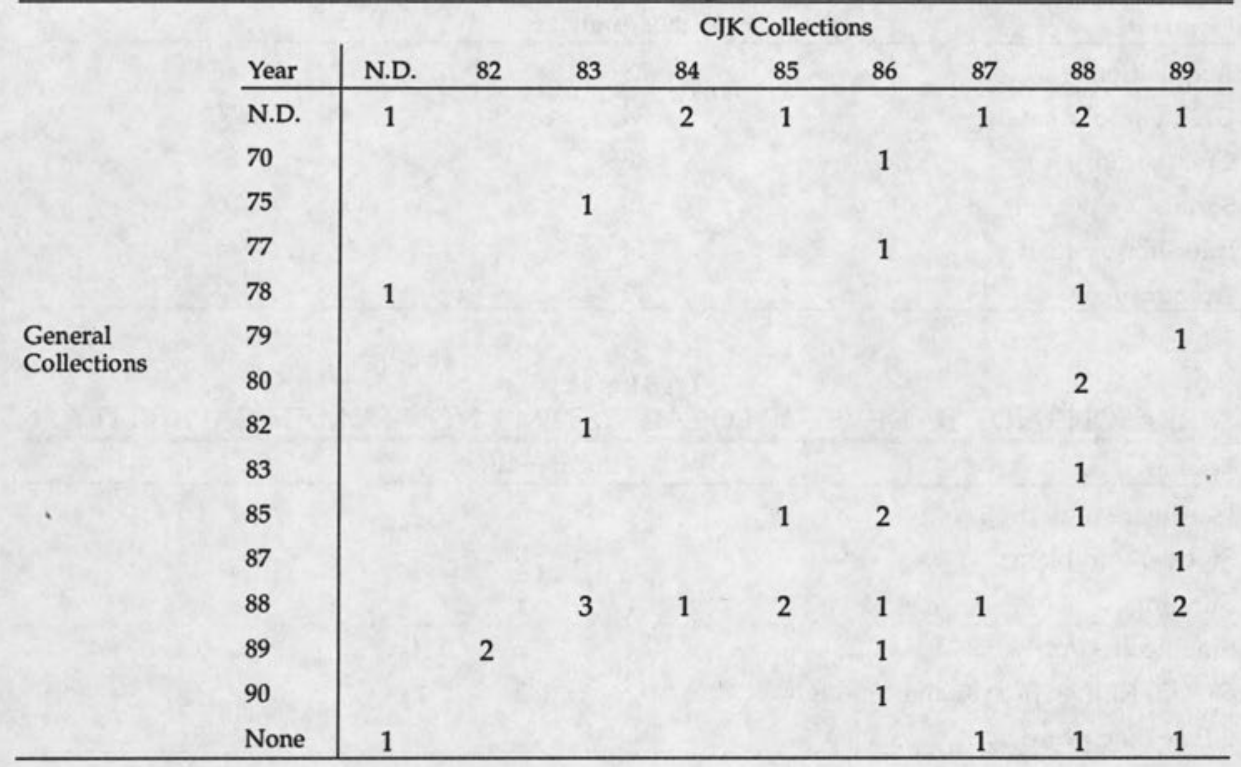

other functions, such as cataloging maintenance and electronic mail service.

Non-Roman Capabilities. Only 27 respondents answered the question concerning their local systems' ability to process and display non-Roman languages. All answers are negative. Twenty-three $(85 \%)$ respondents related the problem to hardware limitations, 22 $(81 \%)$ to software problems, $11(41 \%)$ to insufficient funding, and $5(19 \%)$ to the small size of collections. No respondent thought the problem was due to lack of demand.

Future Development. Twenty-nine libraries responded to the question of whether or not their institutions plan to develop non-Roman capability. Thirteen $(45 \%)$ of them answered yes; however, no clear time frames were given, except for one library that estimated three to five years from now. As for the methods of development, $5(17 \%)$ institutions plan to improve their existing local systems; 1 (13\%) institution plans to purchase separate hardware, but still link up to the local system; $3(10 \%)$ institutions will explore more than one possibility; 2 (7\%) institutions do not have clear ideas on this matter yet; and another $2(7 \%)$ institutions will rely on vendors of their local systems to do it. Sixteen $(55 \%)$ respondents indicated that their institutions will not develop their local automated library systems' nonRoman capabilities. Table 12 lists the selected reasons.

\section{Relations between CJK and Local Systems}

Table 13 shows the statistical outcome of the relationship between CJK systems and local systems. Among 32 respondents to this question, $4(13 \%)$ reported

TABLE 10

METHODS OF DEVELOPMENT OF LOCAL SYSTEMS

\begin{tabular}{lcc}
\hline Methods & $\begin{array}{c}\text { No. of } \\
\text { Institutions }\end{array}$ & $\%$ \\
\hline $\begin{array}{l}\text { Developed in-house } \\
\text { Turn-key systems }\end{array}$ & 10 & 29 \\
$\begin{array}{l}\text { Modified } \\
\text { commercial } \\
\text { systems }\end{array}$ & 13 & 38 \\
\begin{tabular}{l} 
Other \\
\hline
\end{tabular} & 9 & 27 \\
\hline
\end{tabular}


TABLE 11

FUNCTIONS LOCAL SYSTEMS SERVE

\begin{tabular}{lcc}
\hline Functions & No. of Institutions & $\%$ \\
\hline Acquisition & 23 & 68 \\
Online public catalog & 34 & 100 \\
Circulation & 28 & 82 \\
Serials & 20 & 59 \\
Inter-library loan & 14 & 41 \\
Accounting & 19 & 56 \\
\hline
\end{tabular}

TABLE 12

REASONS NOT TO DEVELOP LOCAL SYSTEMS' NON-ROMAN CAPABILITY

\begin{tabular}{lcc}
\hline Reasons & No. of Institutions & $\%$ \\
\hline Hardware limitations & 9 & 56 \\
Software problems & 9 & 56 \\
Funding & 7 & 44 \\
Small collection & 2 & 13 \\
OCLC/RLIN CJK system is enough & 2 & 13 \\
Other (low priority) & 5 & 31 \\
\hline
\end{tabular}

TABLE 13

RELATION BETWEEN CJK SYSTEMS AND LOCAL SYSTEMS

\begin{tabular}{lrrr}
\hline & OCLC Users & RLIN Users & \% of Total \\
\hline $\begin{array}{l}\text { Relation: }(\mathrm{n}=32) \\
\text { Parallel systems }\end{array}$ & 2 & 2 & 13 \\
$\begin{array}{l}\text { Download records from CJK } \\
\text { systems }\end{array}$ & 14 & 14 & 87 \\
$\begin{array}{l}\text { Methods of downloading: }(\mathrm{n}=26) \\
\quad \text { Directly }\end{array}$ & 2 & 2 & \\
$\quad$ Via tapes & 10 & 11 & 15 \\
$\quad$ Other methods & 1 & 0 & 41 \\
Character Treatments $(\mathrm{n}=26)$ & 1 & & \\
$\quad$ Eliminated & 7 & 7 & 31 \\
$\quad$ Stored in local systems & 5 & 6 & 50 \\
$\quad$ Stored in separate tapes/files & & 0 & 19 \\
\hline
\end{tabular}

having parallel systems (a local system for Roman-language materials and a CJK system for East Asian-language materials); $28(88 \%)$ reported that they download records from the online CJK system to the local system. Among the latter, 26 answered questions regarding methods of downloading and the treat- ment of CJK characters: 4 (15\%) institutions download records directly from the CJK system to the local system; 21 ( $81 \%)$ libraries download CJK records to a tape first and then to the local system (either weekly or monthly); and 1 (4\%) library uses other methods. For the treatment of CJK characters during downloading, 8 
(31\%) institutions automatically eliminate them from their local systems; 13 (50\%) institutions store codings representing CJK characters in their local systems, although these are not accessible to the general user; and 5 (19\%) institutions use methods that could be considered compromises between the first two methods - they eliminate CJK characters from their local systems and maintain archival tapes of records containing CJK characters for future use.

\section{DISCUSSION}

The survey results provide the following answers.

Functions. The survey shows that cataloging is the most important function of CJK systems. Although $46 \%$ of the respondents reported using the CJK system as an online public catalog, most of them indicated that this function is not heavily used. Interlibrary loan (record searching and verification only) is the third most important function of the CJK system; however, it is not widely used either. More research and development are needed to enhance or expand the capabilities of these two CJK systems.

Merits and Weaknesses. Although a minor problem occurred in the survey due to the misinterpretation of questions related to benefits and problems of CJK systems, I was able to resolve it by using different analysis methods. The results from group A show the weight of importance of each benefit and problem element; yet the results from vote counts represent the general concern of responding libraries. Although I was not surprised by the different outcomes resulting from these two analysis methods, I was interested to see that there are actually some consistencies between them. For example, both analysis methods indicate that the most important benefit of CJK systems is increased cataloging productivity. High costs also are included in both analysis results as one of the three major problems of CJK systems.

A further examination of the medians of group A in tables $6 c$ and $7 c$ shows that responding libraries weight benefits of CJK systems higher than their problems (the medians for benefits ranged from three to five, and the medians for problems ranged from one to three). This indicates that the merits of the two systems are seen as more important than their problems-perhaps an encouraging outcome for the two systems.

Relations. The majority $(87 \%)$ of responding libraries download records from CJK systems to their local automated library systems. Because none of these local automated library systems has the capability of processing and displaying CJK vernacular characters, $31 \%$ of the responding libraries have to strip off the vernacular fields from the bibliographic records. This situation means that only Romanized bibliographic information is downloaded, and those vernacular characters will never be recovered. Fortunately, the majority of libraries retain vernacular fields either in their local automated systems or on separate tapes. Although they are not able to use them at present, it will be possible to use them if the non-Roman capabilities of their local automated systems are developed in the future.

Future Prospects. Although most libraries wish that the non-Roman capabilities of their local automated systems will be further developed in the future, only $45 \%$ of them reported having plans to do so. The major barriers for the development plan are hardware and software limitations, as well as insufficient funding. Low priority also is an important factor. However, as technology progresses, the hardware and software limitations should be eliminated. The remaining barriers can be removed easily with the continuing commitment from East Asian libraries and their parent institutions. Developing the non-Roman capabilities of local systems will not only solve the problem of CJK materials, but will benefit other non-Roman materials.

For in-house local automated library systems, the development plan might have to be carried out individually. For turn-key or modified commercial systems, the cooperation among libraries using the same system and system vendors will be an efficient and economical solution. 


\section{CONCLUSIONS}

From this study, I conclude that the sharing of cataloging efforts (the financial and human resources) among East Asian libraries has been fully served by the two CJK systems because all member libraries are involved in cataloging activities using the two systems. As the use of these systems for interlibrary loan purposes increases, the sharing of material resources also will improve. (At present, many interlibrary loan bibliographic verifications for old materials are done manually using some major East Asian libraries' printed catalogs, such as the Harvard-Yenching Library Catalog or the Hoover Institution Library Catalog. After each individual library's retrospective conversion project is finished, the use of these two CJK systems for interlibrary loan purposes should increase greatly.)

Nevertheless, the East Asian collections in the United States are still not fully integrated into the main collections of their parent institutions. Most institutions include Romanized CJK records in their local automated library systems. However, these records do not serve many practical purposes because, due to the large number of homophones in CJK languages, Romanized CJK records are not always legible to users or even welltrained librarians. East Asian libraries still rely heavily on the card catalog for public services. The important develop- ments of both OCLC and RLG-that is, OCLC CJK350 and RLIN CJK-are, for the most part, enjoyed only by the cataloging staffs of East Asian libraries. However, their efforts in creating vernacular fields in bibliographic records are diminished later in the process of downloading from CJK systems to local systems. This is a waste of resources not only for East Asian libraries, but for the entire bibliographic community.

\section{The merits of the two systems are seen as more important than their problems-perhaps an encouraging outcome for the two systems.}

To bring East Asian collections and other non-Roman-language collections into the bibliographic mainstream, thus forming a complete automated public access catalog, more effort has to be expended in improving local automated library systems' abilities to accommodate non-Roman capabilities. The initiation and cooperation of East Asian libraries, the expertise of personnel at both OCLC and RLG regarding computer processing of non-Roman languages, as well as the commitment of major academic institutions are the key factors in achieving this goal, whichwe hope-will be achieved in another five to ten years.

\section{REFERENCES AND NOTES}

1. Lucy A. Tedd, "Computer-based Library Systems: A Review of the Last Twenty-one Years," Journal of Documentation 43:145-61 (June 1987).

2. "Five Years of CJK," Research Libraries Group News 17:3 (Fall 1988).

3. Wen-kai Kung, "Computerized Cataloging of East Asian Vernacular Materials in Non-RLIN Libraries of North America," Association for Asian Studies (AAS) Committee on East Asian Libraries (CEAL) Bulletin 80:5-10 (Dec. 1986); Hee-Jung Lee, "A Study of Autcmated Cataloging Systems for Chinese, Japanese, and Korean Materials" M.L.S. specialization paper, (Grad. Sch. of Lib. and Info. Sci., University of California-Los Angeles, 1985); Karen T. Wei, "Current Status and Future Trends of East Asian Library Automation in North America," Information Technology and Libraries 5:140-46 (June 1986).

4. John W. Haegar, "An RLG Plan for the Inclusion of East Asian Records in the Research Libraries Information Network," International Association for Orientalists Librarians (IAOL) Bulletin 24-25:38-43 (1984), and his "RLIN CJK: A Review of the First Five Years," IAOL Bulletin 30-31:18-20 (1987); Jay Lee, "Cataloging CJK Online: The ASIA 
Experience," paper presented to subcommittee on technical processing, CEAL, AAS Conference, Mar. 16, 1989; Alan Tucker, "The East Asian Project of the Research Libraries Group," AAS. CEAL. Bulletin 69:12-24 (Oct. 1982); Andrew Wang, "OCLCCJK Automated Library Information Network," Journal of Library and Information Science (Taipei) 11:143-53 (Oct. 1985); and Karen T. Wei, "RLIN CJK vs. OCLC CJK," Journal of Educational Media and Library Science 24:82-94 (Autumn 1986), in Chinese.

5. Research Libraries Group, RLG CJK Terminal Manual (Stanford, Calif.: Research Libraries Group, 1983), p.25-26.

6. "RLIN MultiScript Workstation Enthusiastically Received," Research Libraries Group press release, May 5, 1989.

7. "Five Years of CJK," Research Libraries Group News, p.3-11.

8. Wang, "OCLC CJK Automated Library Information Network," p.143-53, and system information prepared by him for the author (Jan. 11, 1990).

9. Ibid.

10. "The EPIC Service Is Introduced," OCLC Newsletter 183:10-16 (Jan./Feb. 1990).

11. "Use of OCLC CJK350 System Grows," OCLC Newsletter 181:31 (Sept./Oct. 1989).

12. "OCLC and RLG to Cooperate on Compatibility in Computer Linking," Research Libraries Group press release, May 7, 1990. 


\section{Build Your Future with ABRI}

\section{The library association that}

- contributes to the total professional development of over 10,000 academic and research librarians

- improves service capabilities of academic and research librarians

- promotes and speaks for the interests of academic and research librarianship

- promotes study and research relevant to academic and research librarianship

Membership benefits include free subscriptions to College \& Research Libraries. ACRL's official journal, and College and Research Libraries News. ACRL's news magazine for the profession - a $\$ 50$ value; reduced rates for conference registration and continuing education courses, discounts on ACRL publications - and much more.

The Association of College and Research Libraries is a division of the American Library Association (ALA). ALA membership is prerequisite to ACRL membership.

1

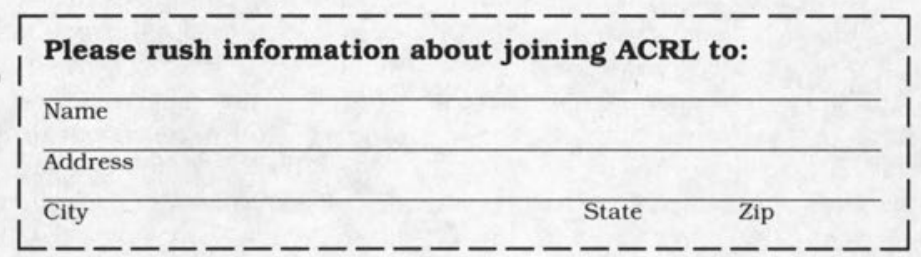

Mail to: Association of College and Research Libraries American

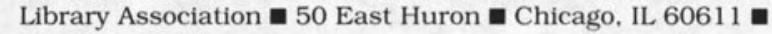

312/944-6780

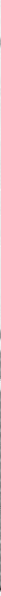

